\title{
Scaffolding problem-based learning with CSCL tools
}

\author{
Jingyan Lu • Susanne P. Lajoie • Jeffrey Wiseman
}

Received: 25 December 2009 /Accepted: 22 June 2010 /

Published online: 10 July 2010

(C) The Author(s) 2010. This article is published with open access at Springerlink.com

\begin{abstract}
Small-group medical problem-based learning (PBL) was a pioneering form of collaborative learning at the university level. It has traditionally been delivered in face-toface text-based format. With the advancement of computer technology and progress in CSCL, educational researchers are now exploring how to design digitally-implemented scaffolding tools to facilitate medical PBL. The "deteriorating patient" (DP) role play was created as a medical simulation that extends traditional PBL and can be implemented digitally. We present a case study of classroom usage of the DP role play that examines teacher scaffolding of PBL under two conditions: using a traditional whiteboard (TW) and using an interactive whiteboard (IW). The introduction of the IW technology changed the way that the teacher scaffolded the learning. The IW showed the teacher all the information shared within the various subgroups of a class, broadening the basis for informed classroom scaffolding. The visual records of IW usage demonstrated what students understood and reduced the need to structure the task. This allowed more time for engaging students in challenging situations by increasing the complexity of the problem. Although appropriate scaffolding is still based on the teacher's domain knowledge and pedagogy experience, technology can help by expanding the scaffolding choices that an instructor can make in a medical training context.
\end{abstract}

Keywords Scaffolding · Role play PBL $\cdot$ Medical education - Content analysis · CSCL . CSCL tools $\cdot$ Argumentation tools $\cdot$ Visualization tools

J. $\mathrm{Lu}(\square)$

The University of Hong Kong, Pokfulam Road, Hong Kong, China e-mail: jingyan@hkucc.hku.hk

S. P. Lajoie

Department of Educational and Counselling Psychology, McGill University, 3700 McTavish Street, Montreal, Canada, QC H3A 1Y2

J. Wiseman

McGill University, Montreal, Canada, QC H3A 1Y2 


\section{Objectives}

Computer-supported collaborative learning (CSCL) environments support collaborative learning by providing visualization and argumentation tools. CSCL tools are used in a variety of domains, such as science (Baker et al. 2001; Baker and Lund 1997; Diehl 2000; Hoadley and Linn 2000; Suthers et al. 2001), mathematics (Baker et al. 1997; Vahey et al. 2000), and writing (Feltovich et al. 1995; Lingnau et al. 2003; Neuwirth and Wojahn 1996). This study examines the use of CSCL in the context of a problem-based learning (PBL) activity in medicine.

PBL is an instructional approach used in medicine where "real-life" cases are presented and students are required to define the problem, create hypotheses, gather and analyze data, and evaluate or justify solutions collaboratively (Barrow 1986; Barrow and Tamblyn 1980; Hmelo-Silver and Barrows 2006). A major goal of the PBL approach in medicine is to train practitioners to function cooperatively in real-world problem-solving situations during their medical careers (Koschmann et al. 1996). Efforts to enhance the effectiveness of PBL activities has led to various innovations (Rendas et al. 1999). This case study examines two such innovations, one is the introduction of a role-play activity, called the "Deteriorating Patient" (DP) (Wiseman and Snell 2008). The second innovation is the introduction of CSCL tools into the PBL activity to facilitate collective problem solving.

This paper describes the nature of scaffolding of collaborative problem solving under two conditions: with technological support and without. In particular, we describe how technology enhances the collaborative problem-solving situation by providing a mechanism for diversified scaffolding support using the DP PBL activity. Such scaffolding goes beyond teacher tutoring. We respond to Pea's (2004) call for using mixed designs for documenting the effectiveness of both human and technology-based scaffolding on learning.

After presenting the theoretical framework grounding this study, we describe the educational context of DP role plays. The methods of analysis are then described in a manner that integrates perspectives on scaffolding, discourse analysis, information technology, and problem solving. The results of the case study elucidate the scaffolding strategies used under the two conditions: with and without support of technology. We conclude by relating the research findings to the theories grounding this study.

\section{Theoretical background}

In this section, we review the literature on CSCL tools, PBL, and scaffolding as they are foundational to this research.

CSCL

CSCL environments typically provide tools that support visualization and argumentation during collaborative problem solving. Visualization tools support collaborative problem solving, allowing learners to construct representations jointly (Roschelle and Teasley 1995) by providing external mental processes in the form of concept maps (Stoyanova and Kommers 2002), diagrams (van Boxtel and Veerman 2001), and text (Hoadley and Linn 2000). Visualizations can foster abstract conceptual understanding by illustrating the relationships between data and evidence (Suthers and Hundhausen 2001) and possibly inducing higher-level discourse through consensus building (Fischer et al. 2002). 
Argumentation tools facilitate structured interaction and argumentation representation. Argumentation tools structure interactions by orienting participants with respect to subject matter by supporting greater coherence in discussions, increasing focus on topics, and consequently reducing off-task talking (Hron et al. 2000). Structuring can be achieved through communication acts (Baker 2003), sentence openers (Baker and Lund 1997; Hirsch et al. 2004), posting notes and making comments (Fischer et al. 2002; Scardamalia and Bereiter 1996), or representing multiple opinions that scaffold students to express their own opinions and integrate the opinions of others (Hoadley and Linn 2000). Visual representations of arguments can serve as external frames for constructing knowledge and solving problems (Hron and Friedrich 2003). They can encourage explicit exploration and negotiation, thus improving the effectiveness of knowledge construction.

In the next session, we introduce PBL and explore how CSCL tools can be integrated into PBL to scaffold learning and teaching.

PBL

Researchers in medical education have argued that problem solving, effective communication, and social skills should be taught together (Barrow 1994; Koschmann et al. 1996; Patel et al. 1991; Schmidt et al. 1996) and PBL was developed to meet these educational goals. PBL activities challenge learners to integrate their declarative medical knowledge and clinical skills while solving "real-life" medical cases that require them to communicate and work collaboratively in small groups (Barrow 1988). PBL facilitators use various strategies to support reasoning, problem solving, self-directed learning, and collaboration skills (Hmelo-Silver and Barrows 2006; Hmelo-Silver et al. 2007).

However, Hoffmann and Ritchie (1997) have argued that PBL activities have three limitations: (a) they lack flexibility in that they are largely text based and consequently learners must rely on information given in the text rather than ask for clarifications beyond preset limits, which is possible in interactive situations; (b) they lack sufficient contextualization and, thus, it is difficult for students to relate PBL scenarios to the realworld situations they purport to represent, and (c) they tend to target cognitive skills rather than affective skills issues (i.e., anxiety about their own problem-solving capabilities, learning to communicate with distraught patients and relatives, etc.).

The DP role-play activity was created to address the limitations of the PBL activities described above by providing students with an interactive, contextualized environment, where both cognitive and affective considerations are met. Teaching medical emergencies demands the design of learning activities that provide students with opportunities to practice dealing with authentic medical emergencies in realistic contexts. The DP activity provides students with a dynamic interactive role-play activity that has the structure of a PBL in that students get to hypothesize and test their solutions. However, instead of reading about a case, the students are role-playing a case where they must manage a deteriorating patient by acting as physicians. The teacher simulates the medical emergency by acting as the patient as well as the duty nurse. The teacher scaffolds students in the context of the emergency. The students view this as an authentic situation where they must manage both their decision making as well as their anxiety about handling the emergency.

Koschmann et al. (1996) described several principles of CSCL environments that could address the limitations of PBL: multiplicity, activeness, authenticity, and articulation. Multiplicity is based on the concept that knowledge is complex, dynamic, context-sensitive, and interactively related. Thus, multiple perspectives, representations, and strategies should be promoted with the support of CSCL tools such as visualization 
tools. Medical PBL cases can be approached from different perspectives, such as basic biomedical medicine, diagnosis, or treatment in CSCL contexts. In addition, collaboration requires activeness and articulation of ideas where students using the PBL method must articulate their actions before group actions are taken. Argumentation tools that are supported with technology can support articulation and decision making within groups.

In this study, we examine the manner in which the teacher scaffolds learning with and without the support of CSCL tools. The next section examines the role of scaffolding.

\section{Scaffolding}

Scaffolding is a pedagogical process whereby more-knowledgeable others help learners perform tasks they cannot do by themselves (Wood et al. 1976; Wood and Middleton, 1975). Scaffolding enables learners to realize their potential by providing assistance when needed and removing or fading it as learning occurs (Collins et al. 1989; Lajoie 2005; Pea 2004).

In the context of PBL activities, facilitators monitor the problem-solving activities of learners who are expected to develop proper mind-sets, engage with problems, and manage problem-solving processes. Researchers have identified various scaffolding strategies for helping learners overcome conceptual and procedural hurdles (Hmelo-Silver and Barrows 2006; Lajoie et al. 2001; Quintana et al. 2004; Reiser 2004). Scaffolding can take many forms. We discuss scaffolding as an element of pedagogical competence, as well as technological support.

Pedagogical competence involves three kinds of knowledge: domain knowledge or subject matter expertise, pedagogical knowledge or knowledge of how to teach, and curriculum knowledge which involves knowledge of how to structure the content knowledge (Shulman 1986). The ability to adapt scaffolding strategies to individual differences varies according to levels of pedagogical competence (Berliner 1988; Graesser et al. 1997; Lepper et al. 1997). Effective teaching involves adapting instruction to individual differences (Cronbach and Snow 1977). Expert teachers use a variety of scaffolding techniques to achieve their instructional goals and they tend to be more student centered, allowing students more control of classroom discourse.

Research has shown that effective PBL teachers provide scaffolds that provide metacognitive guidance about what to think about in the context of the activity as well as scaffolds that promote better collaborations by asking questions pertaining to the construction of explanations. For instance, teachers may ask for explanations in order to make student knowledge more public, to help them see the limitations of their understandings and reasoning (Gilkison 2003; Hmelo 2003). Facilitators may also restate student information to help students' reflect on what they have said or to further explain when necessary (Hmelo-Silver and Barrows 2006). Good facilitators withdraw or fade scaffolding as students demonstrate understanding.

Reiser (2004) argues that scaffolding can be effective when teachers chose to either decrease or increase task complexity. Decreasing task complexity can be accomplished by structuring the task in a manner that directs students' attention to the appropriate task components or guides them in their solution processes. For example, in PBL activities, the teacher can reduce task complexity and cognitive load by writing the problem-solving processes on a whiteboard in a structured format, such as a problem list of patient issues, thereby reducing the complexity of the problem space (Barrow and Tamblyn 1980). On the other hand, an instructor may find that learners need more challenges to stretch their current abilities and choose to scaffold learners by increasing the task complexity. Increasing task 
complexity to challenge learners has been referred to as problematizing. In medical simulations, students become more cognitively and emotionally involved when the patient's vital signs are dynamically updated on the whiteboard. Learners become increasingly accomplished problem solvers given structure and guidance from teachers who scaffold them through coaching, task structuring, and hints (Quintana et al. 2004). On the other hand, learners need to be challenged once they have mastered a certain level of performance, and, thus, scaffolding may involve increasing the task complexity by intensifying the type of patient problems that students will need to address in the real world.

In addition to teacher's deliberately scaffolding learners in the context of problem solving, peers may also scaffold each other in collaborative-learning situations. Furthermore, there are a variety of approaches to designing technology rich learning environments to scaffold learning in complex situations, including the design of CSCL tools to support scaffolding by computers or human tutors (Jonassen and Reeves 1996; Lajoie 2000; Lajoie and Derry 1993; Salomon et al. 1991). As stated earlier, technology can scaffold learning by providing tools to build and externalize representations and discourse that pertain to the joint construction of knowledge. Prior research has demonstrated how computer scaffolding can free up teacher and tutor time for more advanced cognitive scaffolding (Lajoie 2005). Intelligent tutoring systems are designed to scaffold learning by providing adaptive feedback to individual learners dynamically based on updating the learner model in the context actions that they take while problem solving. Learner models help the computer determine what to scaffold, when to scaffold, and when to fade assistance (Lajoie 2005; Pea 2004).

The current case study investigates differences that emerge in a teacher's scaffolding of collaborative problem solving under two instructional conditions: one without technology using a traditional whiteboard (TW) and one with technology using electronic interactive whiteboards (IWs). It was hypothesized that the teacher would vary his scaffolding under the two conditions. The study explored the relationship between human tutoring and technology in the DP activity.

\section{Instructional context}

The instructional context for this case study is the DP activity that was designed by Dr. Jeffrey Wiseman to prepare third-year medical students in internal medicine for their rotation in emergency medicine (Wiseman and Snell 2008). As described earlier, this DP activity has some of the same functions of a PBL activity but goes beyond traditional PBL situations in that it is interactive, contextualized, and intersects cognitive and affective concerns in the context of managing a deteriorating patient in a collaborative setting.

DP role plays simulate the medical emergencies that students will encounter in hospital wards and emergency rooms. In DP role plays, students play the roles of "on call" student, junior, and senior residents who must deal with a patient whose medical condition suddenly begins to deteriorate. The teacher plays two roles (beyond that of being the teacher), one as the duty nurse and one as the patient. The students work collaboratively as the physician who must figure out how to stabilize the patient before the patient dies. As the problem progresses, the patient's signs and symptoms grow increasingly life threatening. Students are forced to make quick decisions based on the patient's deteriorating condition.

In each DP role-play scenario, the teacher first explains how the activity works in terms of the various roles that are played, and then the students and the teacher engage in the DP activity, solving the problem by playing their respective roles. While solving the problem, 
the teacher presents the patient case and asks for a student volunteer to start dealing with the patient's deteriorating condition. Students ask the nurse questions about the patient's medical situation, such as vital signs, breathing, circulation, and other important factors in an emergency medicine. On the one hand, student questioning is guided by the "ABCDEF" emergency algorithm where A stands for Airways, B for Breathing, C for circulation, Central Nervous System and Cervical Spine, D for drugs, E for Environment and Endometabolism, and F for fever (Cooper et al. 2006). On the other hand, student questioning is also guided by feedback from the duty nurse's reports on the patient's vital sign status, requested lab results, and the patient's physical appearance. When the student runs into difficulty, the teacher prompts him or her to call for help from the junior resident whose role is assigned to another student volunteer. When the "junior resident" reaches an impasse, s/he calls the "senior resident" who is played by a third student volunteer. In this way, the activity simulates the manner in which real medical emergencies typically unfold.

DP role plays were originally designed to allow individual students to take turns treating the DP. However, due to time limitations, only about half the students in a class were able to participate in each one-hour role play. Other students could only sit and watch their classmates. This case study introduced two changes to the DP role-play activity. The first change was introducing collaboration. Students would work in small groups of two or three rather than individually. In this way, students would have the benefit of collaboration in managing a medical emergency and all students would participate rather than observe the activity. The second change was the introduction of technology to support collaboration. This case study examines the type of teacher scaffolding provided to students under two conditions: collaborative problem solving with and without technological support. The scenario was the same under both conditions. Differences in the two conditions are discussed below.

\section{Methodology}

Two conditions using the DP activity were examined in this study: Traditional Whiteboard (TW) and Interactive Whiteboard conditions (IW). Under both conditions, students were divided into three subgroups in order to play one of the three roles: student, junior resident, or senior resident. Each subgroup took turns interacting with the teacher so that everyone got a chance to work on solving the problem. In the TW condition, subgroups had access to a traditional front-of-the-class whiteboard where the teacher documented the medical emergency and the students' actions taken in response to changes in the "patient." In the IW condition, subgroups had technological support. More specifically, groups had networked laptops linked to an interactive whiteboard where they could access what the teacher wrote on the traditional whiteboard as well as add their own annotations to the patient chart, and share their arguments, hints, and suggestions with students in their own and in the other two subgroups. The teacher is an expert medical educator with 30 years of clinical and teaching experience who was blinded to the research questions of this study.

\section{Data sources}

Two groups of third-year medical students doing their rotation in the Department of Internal Medicine in a large urban teaching hospital volunteered to participate in this study. All the volunteers were receiving the same clinical training in the same teaching hospital. Given the entry requirements for their program of study, it can be assumed that differences in 
background knowledge would be minimal. The students participated in DP role plays at the beginning and at the end of their two-month rotation. For the purpose of this study, data from cases at the beginning of the rotation were collected. Audio/video data of the DP PBL role-play discourse were transcribed and analyzed.

\section{CSCL tools}

This study used a wireless interactive whiteboard with Bluetooth technology. A receiver is connected via Bluetooth to a computer acting as a server which, in turn, was connected to a wireless router enabling three wireless laptops to operate on a local network. Each of the three IW subgroups had a laptop which they use to communicate with the other subgroups via interactive whiteboard software. The interactive whiteboard electronically captures notes and images that are written on the traditional whiteboard in real time into its software "meeting application," and can simultaneously appear on the three subgroup laptops. CSCL tools were designed and integrated into the interactive whiteboard to support collaborative problem solving. The tools support shared visualization and collaborative argumentation. These tools are described below.

\section{Shared visualization tools}

Shared visualization tools facilitate collaborative problem solving by enabling users to construct shared problem spaces. Interactive whiteboards can display in real time the representations of the actions of individual role-playing students as well as those who are observers. The interactive whiteboard condition provided content specific menus where individuals could add information about structured content specific information about the patient history, vital signs, prescriptions, and decisions (see Fig. 1). The structure is similar to the patient's chart in the hospital. Brief history refers to the chief complaint and the major

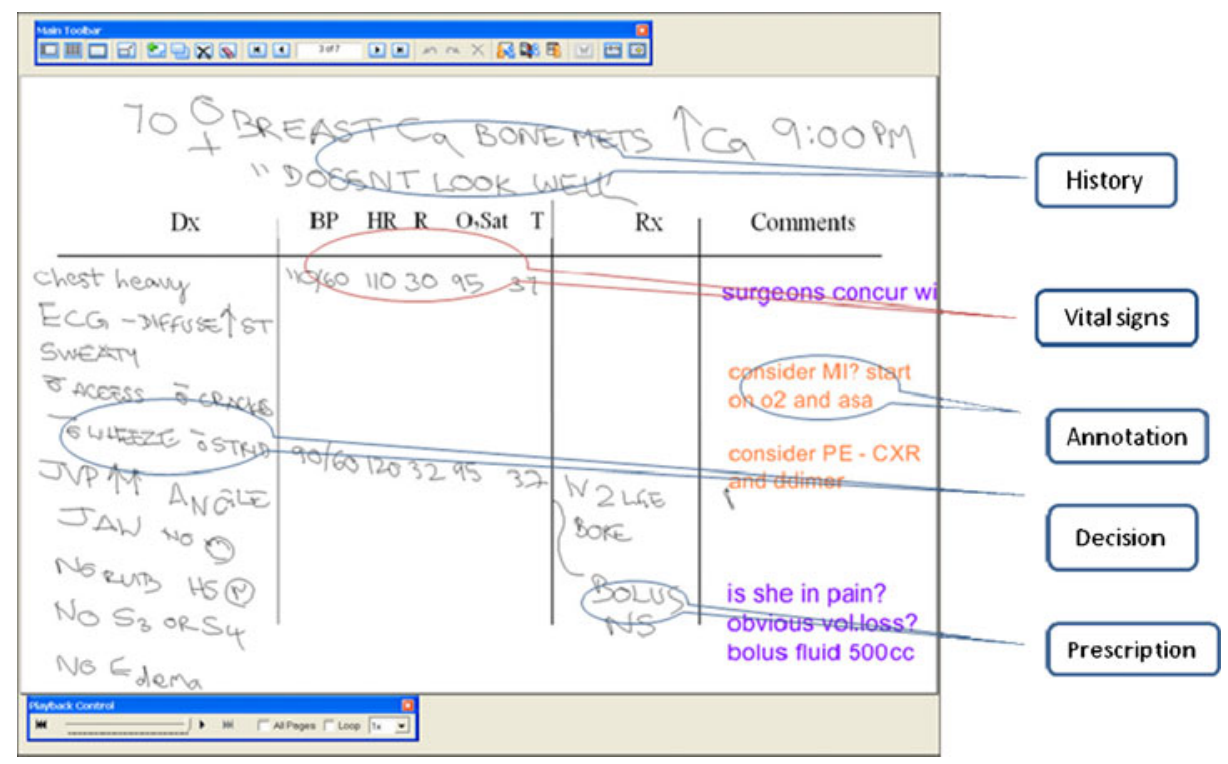

Fig. 1 Screenshot of eBeam whiteboard 
reason why the patient needs immediate attention. Vital signs refer to the patient's heart rate, blood pressure, temperature, respiratory rate, and oxygen saturation. Decisions refer to the kinds of information students (on-call students, junior residents, and senior residents) want to get about the patient and the examination they run, for example, "check airway." Prescription refers to the medication or management given to the patient, for example, "put oxygen, 50\%, on mask." Some modifications are made in order to make the change of problem space obvious so that students could recognize the pattern of the problem. For example, patient vital signs are put in the middle to highlight the deteriorating situation of the patient. Decisions and prescriptions are marked down parallel to the changing vital signs to demonstrate the connection of these three kinds of information.

\section{Collaborative argumentation tools}

Collaborative argumentation tools allow observing students to play an active role by annotating, commenting on, and suggesting alternatives to decisions of role playing on-call students. These tools allow observers to participate and to scaffold collaborative decision making by promoting the discussion of various proposed actions and plans. Students are encouraged to give all kinds of comments, either clinical suggestions, such as "listen to the lungs" or biomedical interpretation, such as "relevance of prednisone." It is hoped that, in so doing, the tools can help learners construct connections between biomedical and clinical knowledge which will further enhance the ability of students to acquire higher cognitive and metacognitive skills.

\section{Data analysis}

DP role plays were videotaped and transcribed. Transcriptions of DP role plays were divided into two parts corresponding to the early and late phases of the activity to better serve the data analysis (will be further elaborated in the results section). Qualitative and content analysis methods were used to identify and explain both the scaffolding strategies and the discourse patterns used in both conditions. Both top-down and bottom-up analyses were used to code the scaffolding data. Top-down analyses were based on previous scaffolding research (Hmelo-Silver and Barrows 2006; Pea 2004; Reiser 2004) but new codes emerged as well.

During DP role plays, students were encouraged to make fast and accurate decisions and to communicate their knowledge, decisions, and actions to the next student taking on the role of "resident." The teacher's strategies for helping students achieve these goals depended on the role that he was playing. As duty nurse, he provided students with information about the patient by responding to their questions about the patient, by reporting the results of their patient management actions, and by creating new situations (either improving or deteriorating the patient) to foster student reflection. As instructor, the teacher monitored group dynamics in order to ensure that the rules of the role play and of emergency medicine were adhered to, and that students were working collaboratively.

Content analysis was used to characterize discourse patterns and functions among students and teacher in order to elaborate our findings on scaffolding strategies. Codes for scaffolding strategies used by the teacher as nurse, as patient, and as instructor were adapted from published research (Hmelo-Silver 2002, 2003; Quintana et al. 2004). Discourse functions were identified by coding the teacher's utterances as the duty nurse and the instructor. As instructor, he provided domain-unspecific (external, independent) information such as rules or managing the groups, and domain-specific (internal, dependent) 
information, such as elaborating the laboratory tests. Discourse patterns were identified as the types of discourse the teacher used as the nurse. He: (a) provided information requested (IR), for example, in responding to student's inquiry "What is the EKG like?", the Nurse said "And EKG shows sinus tachycardia, and no change from previous, shows some old $Q$ waves, and these inferior waves"; (b) provided new information (NI), for example, while student did something wrong or failed to do the right thing, the Nurse said "And at this point, the patient is quite somnolent" by reminding them the deteriorating situation of the patient; (c) asked verification or clarification questions (Q), for example, the Nurse asked clarification questions about how to give oxygen " $35 \%$, by mask?" when the student gave an incomplete order; and (d) repeated or confirmed with questioning intonations to get students to elaborate on their reasoning (R). Two raters coded the transcripts independently; the inter-rater consistency is above $90 \%$. Table 1 provides definitions and examples.

Scaffolding strategies, which we emphasized here in this paper as the teacher either decreased task complexity (by structuring the task) or increased the task complexity (by creating new challenges) for students, are described below.

\section{Research questions}

The two conditions introduced in this research were intended to be more inclusive of students by providing collaboration opportunities while solving DP scenarios. However, we were interested in whether or not the introduction of technology in this collaborative situation influenced the nature of the teachers' scaffolding. In a previous paper, we examined student performance in both conditions and found that students in the technology condition performed better in that they were able to arrive at decisions earlier which led to better patient management ( $\mathrm{Lu}$ and Lajoie 2008). Our assumption was that better performance was due to the externalization of student actions in the interactive whiteboards as well as the interactions and argumentation that these annotations provided. However, the goal of this paper is to examine the teacher's scaffolding strategies in more detail. Based on this rationale, we have the following research questions.

1. What scaffolding strategies and discourse patterns does the teacher display during the DP role plays under the two conditions?

2. If there are scaffolding and discourse differences in the two conditions, can they be explained by the role of technology?

Table 1 Discourse functions of the teacher discourse

\begin{tabular}{|c|c|c|}
\hline $\begin{array}{l}\text { Discourse } \\
\text { Function }\end{array}$ & Definition & Example \\
\hline IR & $\begin{array}{l}\text { Provide information to questions asked } \\
\text { by students }\end{array}$ & $\begin{array}{l}\text { Student: What is the EKG like? } \\
\mathrm{N} \text { : And EKG shows sinus tachycardia, and no change } \\
\text { from previous, shows some old Q waves, and these } \\
\text { inferior waves }\end{array}$ \\
\hline NI & $\begin{array}{l}\text { Provide new information, explanation or } \\
\text { justification not asked for by the } \\
\text { student }\end{array}$ & $\mathrm{N}$ : And at this point, the patient is quite somnolent, \\
\hline Q & Yes/No questions or WH-questions & $\mathrm{N}: 35 \%$, by mask? \\
\hline $\mathrm{R}$ & Repeat or confirm & N: What vitals are you interested in? \\
\hline
\end{tabular}




\section{Results}

In this section, we identify and compare discourse patterns, functions, and scaffolding strategies that the teacher used during DP role plays under the two conditions, with (TW) and without (IW) technological support.

\section{Discourse patterns}

In the IW condition, the teacher initiated more new information or challenging situations (NI) and repeated or confirmed student responses with a questioning intonation (R). On the other hand, in the TW condition, the teacher provided more information that was asked by the students (IR) and asked clarification questions (Q) from the students (Fig. 2). The teacher tended to increase the complexity of the DP activity in the technology condition by creating new or more challenging situations and decrease the complexity in the traditional condition by providing required information and asking clarification questions. These scaffolding strategies differences were consistent in the two conditions.

The teacher increased the complexity of the problem by compelling students to deal with different and unexpected complications so as to extend their problem-solving abilities. Given the activity is interactive, the teacher must adjust his strategies based on the different ways that students address the problems. The teacher increases task complexity by updating the patient's deteriorating vital signs in response to what students did or did not do as a way of focusing the students' attention on the patient's dire medical condition that must be managed or the patient expires. The following excerpt presents a sample communication between L (student) and the Nurse that illustrates how the teacher increases the task complexity.

L: Portable chest X-ray.

Nurse: OK, while you are waiting for the portable chest X-ray, the nurse tells you the blood pressure is now 80 over 40 , heart rate is now 138 per minute, respiratory rate is 32 per minute and Oxygen saturation is 94 percent and the temperature is 38 , and the patient looks sleepy.

$\mathrm{L}$ had asked for a portable chest X-ray based on the patient's medical history of pneumonia. The teacher responds to L's request by deteriorating the patient's blood pressure, heart rate, respiratory rate, Oxygen saturation, temperature, and mental state. This was his way of telling

Fig. 2 Frequency distribution of discourse as Nurse and Instructor, and Domain discourse and Rule discourse in early and late stages in IW and TW conditions

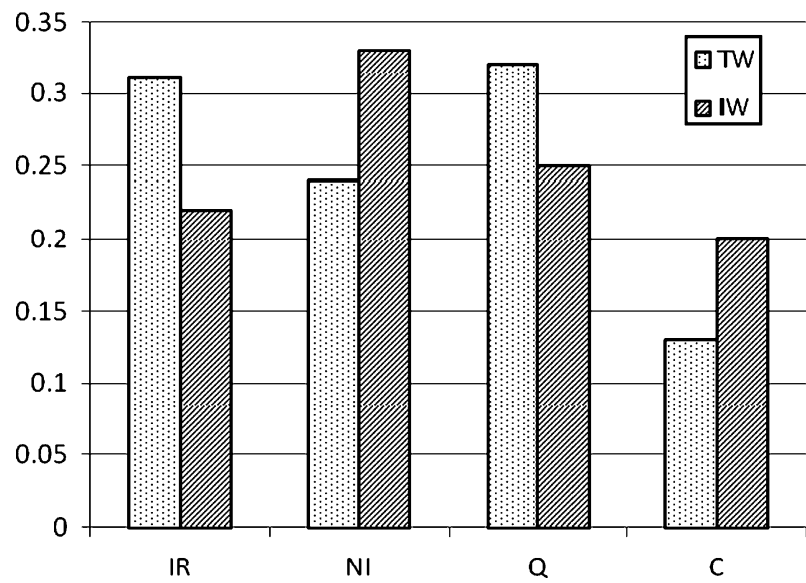


them that doing an X-ray right at that time was not a good idea. The teacher increased the complexity of the situation to push L to seek a more effective way of helping the patient.

The nature and extent of teacher scaffolding differed by condition in terms of whether the teacher increased or decreased task complexities. The teacher decreased the task complexity for the TW group because they were struggling to understand the situation and increased the task complexity for the technology group to further challenge their problemsolving abilities which were facilitated and improved by technology (Lu and Lajoie 2008).

\section{Discourse functions}

The teacher also varied his roles in the two conditions, with respect to the frequency of when he spoke as a nurse or as an instructor. In order to examine the teacher's roles in the discourse as to when and why he used the nurse and instructor discourse in the two conditions, we divided the DP role play into two stages, an early and late stage in the activity. Students spend more time asking questions in the early stage of problem solving that pertain to the ABCDEF emergency algorithm. They asked fewer questions in the later stage and communication was more about managing the patient's deteriorating medical condition. In general, the teacher spent more time decreasing the task complexity in the early stage to help students construct the problem space whereas the teacher could increase the task complexity to extend students' problem-solving capacity in the later stage. The later stage is more challenging for students given their lack of expertise which may limit their focus on issues salient to specific situations.

The teacher spoke as instructor in order to manage group dynamics and to provide domain knowledge. In the early stage, the teacher helped students attain a good understanding of the problem by playing the role of the nurse, providing patient information and sometimes elaborated on the information provided by students. Occasionally, as instructor, he managed the group dynamic to keep students on track. Thus, the instructor used his domain knowledge and pedagogical competence to scaffold the groups. Scaffolding techniques in the early stage included specifying role-play rules (Instructor), creating the problem space by providing the required information (nurse) and managing the role-play dynamics (Instructor).

Condition differences were found in the type of nurse and instructor discourse in both stages but more so in the late stage. Both the nurse and instructor discourse decreased in the late stage in the IW condition while the opposite was true in the TW condition (see Fig. 3a). As stated earlier, the late stage of problem solving is more complex. It is interesting to note that the group that was supported by IW needed less scaffolding than those in the TW condition. Furthermore, the content of the scaffolding differed for the two conditions. The teacher increased scaffolding from the early to late stage for the TW condition for help with rules and domain knowledge whereas he decreased such scaffolding for the IW from early to late stage (see Fig. 3b).

\section{Discussion}

This case study examined the roles of human and computer scaffolding in a role-play medical emergency. We characterize scaffolding in the context of a role play-based PBL, the DP, and explore how scaffolding strategies are presented by a teacher in this role play and how scaffolding is supported through visual artifacts provided through technology. By providing a visual record of their activities, the technology structured students by helping 
Fig. 3 Percentage

of discourse functions

as the Nurse in TW and IW conditions
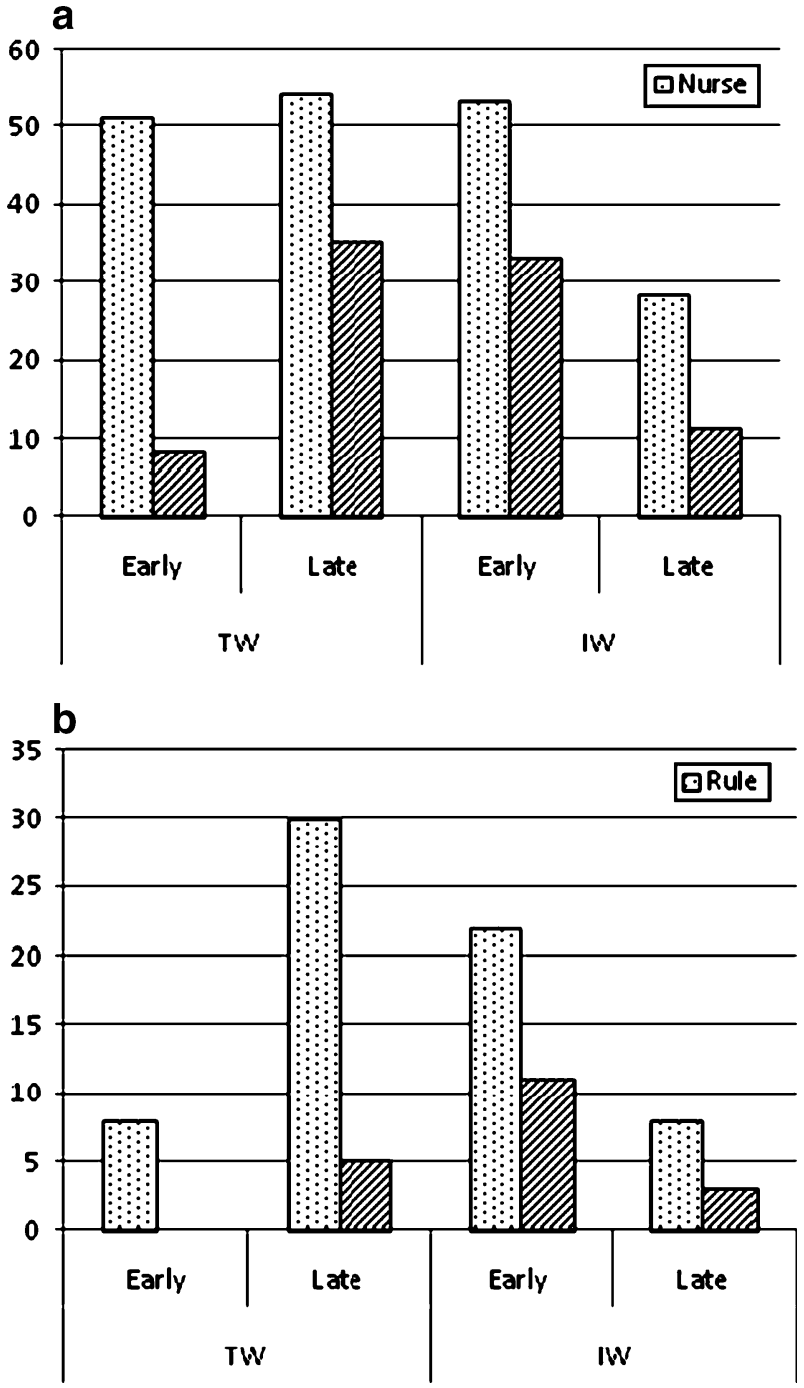

them visualize a dynamically emerging joint problem space which facilitated collaboration and argumentation and, thus, the teacher needed to spend less time providing cognitive assistance (Pea 2004).

\section{Scaffolding strategies}

Scaffolding plays a role in many learning activities including PBL activities (Hmelo-Silver et al. 2007; Nussbaum 2002; Palincsar 1986). However, its function is determined by the limitations on PBL activities identified by Hoffmann and Ritchie (1997). The DP role play overcame the limitations of traditional PBL by making the activities interactive, contextualized, and including both cognitive and affective dimensions to patient management. Given the dynamic nature of the DP activity, the teacher was free to adapt his scaffolding strategies based on the demands on the learners. 
The two most common scaffolding strategies used in the problem-solving phase involved either decreasing or increasing task complexity. The teacher decreased the task complexity by structuring the task, providing both domain specific and non-domain specific guidance. Domain-specific guidance included case-related information and the domaingeneral guidance pertained to peripheral information about rules of the hospital hierarchy and the management of group collaboration. Structuring non-domain specific activities is important in medical education because specialists often collaborate on patient cases. Such specialists interact within the hospital hierarchy. The teacher increased task complexity (challenging the student) in the later phases of problem solving. For example, the teacher might direct the groups attention toward an issue that needs resolution, trigger an affective component that could create interest in advancing understanding, or establish a sense of dissonance or curiosity, or more generally, engage students by increasing the challenge (Reiser 2004). The teacher deteriorated the patient's vital signs, created unexpected situations, and forced students to use their domain knowledge to interpret the patient's medical condition.

\section{Scaffolding with technology}

Whiteboards are CSCL tools. They help learners build joint problem spaces and allow them to refer to the problem-solving history (Barrow 2000; Hmelo-Silver 2004). Interactive whiteboards provided both visualization and argumentation tools which supported goal setting, help seeking, time management, and planning (Dabbagh and Kitsantas 2005). Students using interactive whiteboards demonstrated more adaptive problem-solving behavior than those using only traditional whiteboards ( $\mathrm{Lu}$ and Lajoie 2008). Interactive whiteboards mediated the teacher's scaffolding by increasing class participation. In the IW group condition, the teacher created his scaffolding strategies based on what was recorded and shared using this technology by all subgroups, broadening the basis for classroom scaffolding. Moreover, the nurse talked less in the IW group than in the TW group. As to discourse patterns, in the IW group, the nurse tended to create more new situations and to increase the problem complexity, while in the TW group the nurse tended to engage in more task structuring by asking verification and clarification questions and by providing students with required information. This is consistent with our earlier findings (Lu and Lajoie 2008), concluding that students using IW tended to engage in more adaptive problem-solving behavior. The findings imply that as the teaching environment became more complex so did the teacher's role in scaffolding.

\section{Conclusion}

This case study examined how a medical teacher scaffolded collaborative medical problem solving by using various strategies while playing different roles with the support of technology. The study suggests that scaffolding is most effective when teachers possess both domain knowledge and pedagogy experience, scaffold students' cognitive needs in the authentic medical context, and employ technology design in accordance with basic principles of learning. Visualization and argumentation tools can be designed in CSCL environments to facilitate students' problem solving by promoting collaboration and shared understanding. Such tools also mediate the teachers scaffolding by freeing up their time to extend student abilities with greater challenges based on the shared problem- solving space of the group rather than scaffold the rules of the activity. 
Open Access This article is distributed under the terms of the Creative Commons Attribution Noncommercial License which permits any noncommercial use, distribution, and reproduction in any medium, provided the original author(s) and source are credited.

\section{References}

Baker, M. (2003). Computer-mediated argumentative interactions for the co-elaboration of scientific notions. In J. Andriessen, M. Baker, \& D. Suthers (Eds.), Arguing to learn: Confronting cognitions in computersupported collaborative learning (pp. 47-78). Dordrecht: Kluwer Academic.

Baker, M., \& Lund, K. (1997). Promoting reflective interactions in a CSCL environment. Journal of Computer Assisted Learning, 13, 175-193.

Baker, M., Cohen, J. L., \& Moeller, B. (1997, December). KidCode: Using email to structure interactions for elementary mathematics instruction. Paper presented at the Second International Conference of Computer-Supported Collaborative Learning Toronto, Canada.

Baker, M., de Vries, E., Lund, K., \& Quignard, M. (2001, March). Computer-mediated epistemic interactions for co-constructing scientific notions: Lessons learned from a five-year research program. Paper presented at the First European Conference on Computer-Supported Collaborative Learning, Maastricht, Netherlands.

Barrow, H. S. (1986). A taxonomy of problem-based learning methods. Medical Education, 20, 481-486.

Barrow, H. S. (1988). The tutorial process. Springfield: Southern Illinois University Press.

Barrow, H. S. (1994). Practice-based learning: Problem-based learning applied to medical education. Springfield: SIU School of Medicine.

Barrow, H. S. (2000). Problem-based learning applied to medical education. Springfield: Southern Illinois University Press.

Barrow, H. S., \& Tamblyn, R. (1980). Problem-based learning: An approach to medical education. New York: Springer.

Berliner, D. (1988). The development of expertise in pedagogy. Charles W. Hunt Memorial Lecture presented at the annual meeting of the American Association of Colleges for Teacher Education, New Orleans.

Collins, A., Brown, J. S., \& Newman, S. (1989). Cognitive apprenticeship: Teaching the craft of reading, writing and mathematics. In L. B. Resnick (Ed.), Knowing, learning, and instruction: Essays in honor of Robert Glaser (pp. 453-494). Hillsdale: Erlbaum.

Cooper, N., Forrest, K., \& Cramp, P. (2006). Essential guide to acute care (2nd ed.). Malden: Blackwell Publishing.

Cronbach, L. J., \& Snow, R. E. (1977). Aptitudes and instructional methods: A handbook for research on interactions. New York: Irvington.

Dabbagh, N., \& Kitsantas, A. (2005). Using web-based pedagogical tools as scaffolds for self-regulated learning. Instructional Science, 33(5), 513-540.

Diehl, C. L. (2000, April). “Reasoner's Workbench" program supports students' individual and collaborative argumentation. Paper presented at the annual meeting of the National Association for Research and Science Teaching, New Orleans, LA.

Feltovich, P. J., Spiro, R. J., \& Coulson, R. L. (1995). Learning, teaching, and testing for complex conceptual understanding. In N. Frederiksen, R. J. Mislevey, \& I. I. Bejar (Eds.), Test theory for a new generation of tests (pp. 181-217). Hillsdale: Erlbaum.

Fischer, F., Bruhn, J., Grasel, C., \& Mandl, H. (2002). Fostering collaborative knowledge construction with visualization tools. Learning and Instruction, 12, 213-232.

Gilkison, A. (2003). Techniques used by 'expert' and 'non-expert' tutors to facilitate problem-based learning tutorials in an undergraduate medical curriculum. Medical Education, 37(1), 6-14.

Graesser, A. C., Bowers, C., \& Hacker, D. J. (1997). An anatomy of naturalistic tutoring. In K. Hogan \& M. Pressley (Eds.), Scaffolding student learning: Instructional approaches and issues (pp. 145-184). Cambridge: Brookline Books.

Hirsch, L., Saeedi, M., Cornillon, J., \& Litosseliti, L. (2004). A structured dialogue tool for argumentative learning. Journal of Computer Assisted Learning, 20, 72-80.

Hmelo, C. E. (2003, January). Facilitating collaborative knowledge construction. Paper presented at the 36th annual Hawaii International Conference on System Sciences, Big Island, Hawaii.

Hmelo-Silver, C. E. (2002). Collaborative ways of knowing: Issues in facilitation. Paper presented at the International Conference on Computer-Supported Collaborative Learning (CSCL), Boulder, Colorado.

Hmelo-Silver, C. E. (2003). Facilitating collaborative knowledge construction. Paper presented at the 36th Annual Hawaii International Conference on System Sciences (HICSS'03), Big Island, Hawaii. 
Hmelo-Silver, C. E. (2004). Problem-based learning: What and how do students learn? Educational Psychology Review, 16(3), 235-266.

Hmelo-Silver, C. E., \& Barrows, H. S. (2006). Goals and strategies of a problem-based learning facilitator. The Interdisciplinary Journal of Problem-based Learning, 1(1), 21-39.

Hmelo-Silver, C. E., Duncan, R. G., \& Chinn, C. A. (2007). Scaffolding and achievement in problem-based and inquiry learning: A response to Kirschner, Sweller, and Clark (2006). Educational Psychologist, 42(2), 99-107.

Hoadley, C. M., \& Linn, M. C. (2000). Teaching science through online, peer discussions: SpeakEasy in the knowledge integration environment. International Journal of Science Education, 22, 839-857.

Hoffmann, B. O. B., \& Ritchie, D. (1997). Using multimedia to overcome the problems with problem based learning. Instructional Science, 25(2), 97-115.

Hron, A., \& Friedrich, H. F. (2003). A review of web-based collaborative learning: Factors beyond technology. Journal of Computer Assisted Learning, 19(1), 70-79.

Hron, A., Hesse, F. W., Cress, U., \& Giovis, C. (2000). Implicit and explicit dialogue structuring in virtual learning groups. British Journal of Educational Psychology, 70, 53-64.

Jonassen, D. H., \& Reeves, T. C. (1996). Learning with technology: Using computers as cognitive tools. In D. H. Jonassen (Ed.), Handbook of Research for Educational Communications and Technology (pp. 693-719). New York: Simon and Schuster.

Koschmann, T., Kelson, A. C., Feltovich, P. J., \& Barrow, H. S. (1996). Computer-supported problem-based learning: A principled approach to the use of computer in collaborative learning. In T. Koschmann (Ed.), CSCL: Theory and practice of an emerging paradigm (pp. 1-23). Mahwah: Erlbaum.

Lajoie, S. P. (Ed.). (2000). Computer as cognitive tools: No more walls. Mahwah: Erlbaum.

Lajoie, S. (2005). Extending the scaffolding metaphor. Instructional Science, 33(5), 541-557.

Lajoie, S. P., \& Derry, S. (Eds.). (1993). Computers as cognitive tools. Hillsdale: Erlbaum.

Lajoie, S. P., Faremo, S., \& Wiseman, J. (2001). Identifying human tutoring strategies for effective instruction in internal medicine. International Journal of Artificial Intelligence in Education, 12, 293-309.

Lepper, M. R., Drake, M., \& O’Donnell-Johnson, T. M. (1997). Scaffolding techniques of expert human tutors. In K. Hogan \& M. Pressley (Eds.), Scaffolding studnet learning: Instructional approaches and issues (pp. 108-144). Cambridge: Brookline Books.

Lingnau, A., Hoppe, H. U., \& Mannhaupt, G. (2003). Computer supported collaborative writing in an early learning classroom. Journal of Computer Assisted Learning, 19(2), 186-194.

Lu, J., \& Lajoie, S. P. (2008). Supporting medical decision making with argumentation tools. Contemporary Educational Psychology, 33, 425-442.

Neuwirth, C. M., \& Wojahn, P. G. (1996). Learning to write: Computer support for a cooperative process. In T. Koschmann (Ed.), CSCL: Theory and practice of an emerging paradigm (pp. 147-170). Mahwah: Erlbaum.

Nussbaum, E. M. (2002). Scaffolding argumentation in the social studies classroom. The Social Studies, 93 (2), 79 .

Palincsar, A. S. (1986). The role of dialogue in providing scaffolded instruction. Educational Psychologist, 21(1-2), 73-98.

Patel, V. L., Groen, G. J., \& Norman, G. R. (1991). Effects of conventional and problem-based medical curricula on problem solving. Academic Medicine, 66(7), 380-389.

Pea, R. D. (2004). The social and technological dimensions of scaffolding and related theoretical concepts for learning, education, and human activity. Journal of the Learning Sciences, 13(3), 423-451.

Quintana, C., Reiser, B. J., Davis, E. A., Krajcik, J., Fretz, E., Duncan, R. G., et al. (2004). A scaffolding design framework for software to support science inquiry. Journal of the Learning Sciences, 13(3), 337-386.

Reiser, B. J. (2004). Scaffolding complex learning: The mechanisms of structuring and problematizing student work. Journal of the Learning Sciences, 13(3), 273-304.

Rendas, A., Pinto, P. R., \& Gamboa, T. (1999). A computer simulation designed for problem-based learning. Medical Education, 33(1), 47-54.

Roschelle, J., \& Teasley, S. D. (1995). The construction of shared knowledge in collaborative problem solving. In C. E. O’Malley (Ed.), Computer-supported collaborative learning (pp. 69-97). New York: Springer-Verlag.

Salomon, G., Perkins, D. N., \& Globerson, T. (1991). Partners in cognition: Extending human intelligence with intelligent technologies. Educational Researcher, 20(3), 2-9.

Scardamalia, M., \& Bereiter, C. (1996). Computer support for knowledge-building communities. In T. Koschmann (Ed.), CSCL: Theory and practice of an emerging paradigm (pp. 249-268). Mahwah: Erlbaum.

Schmidt, H. G., Machiels-Bongaerts, M., Hermans, H., ten Cate, T. J., Venekamp, R., \& Boshuizen, H. P. (1996). The development of diagnostic competence: Comparison of a problem-based, an integrated, and a conventional medical curriculum. Academic Medicine, 71, 658-664. 
Shulman, L. S. (1986). Those who understand: Knowledge growth in teaching. Educational Researcher, 15 (2), 4-14.

Stoyanova, N., \& Kommers, P. (2002). Concept mapping as a medium of shared cognition in computer-supported collaborative problem solving. Journal of Interactive Learning Research, 13, 111-133.

Suthers, D., \& Hundhausen, C. (2001, March). Learning by constructing collaborative representations: An empirical comparison of three alternatives. Paper presented at the First European Conference on Computer-Supported Collaborative Learning, Maastricht, Netherlands.

Suthers, D., Connelly, J., Lesgold, A., Paolucci, M., Toth, E., Toth, J., et al. (2001). Representational and advisory guidance for students learning scientific inquiry. In K. D. Forbus \& P. J. Feltovich (Eds.), Smart machines in education: The coming revolution in educational technology (pp. 7-36). Menlo Park: AAAI/Mit Press.

Vahey, P., Enyedy, N., \& Gifford, B. (2000). Learning probability using a collaborative, inquiry-based simulation environment. Journal of Interactive Learning Research, 11(1), 51-84.

van Boxtel, C., \& Veerman, A. (2001, March). Diagram-mediated collaborative learning: Diagrams as tools to provoke and support elaboration and argumentation. Paper presented at the first European Conference on Computer-Supported Collaborative Learning, Maastricht, Netherlands.

Wiseman, J., \& Snell, L. (2008). The deteriorating patient: A realistic but 'low-tech' simulation of emergency decision-making. The Clinical Teacher, 5, 93-97.

Wood, D., \& Middleton, D. (1975). A study of assisted problem-solving. British Journal of Psychology, 66 (2), 181-191.

Wood, D., Bruner, J. S., \& Ross, G. (1976). The role of tutoring in problem solving. Journal of Child Psychology \& Psychiatry \& Allied Disciplines, 17(2), 89-100. 